\title{
Reinserção Social de Psicóticos: Avaliação Global do Grau de Assertividade, em Situações de Fazer e Receber Crítica
}

\author{
Marina Bandeira 123 \\ Esther deMatos Ireno \\ Universidade Federal de São João del Rei, Minas Gerais
}

\begin{abstract}
Resumo
Avaliou-se a assertividade de 35 pacientes psicóticos, comparativamente a 35 participantes de um grupo não-clínico, através de escala tipo Likert de 5 pontos ou cotas, em situaçoes de fazer e receber críticas. Dois observadores avaliaram o comportamento dos participantes em desempenho de papéis gravados em vídeo. Para cada tipo de situação, variou-se o gênero do interlocutor. Os resultados mostraram um déficit significativo de assertividade global, verbal e não-verbal, dos pacientes comparativamente ao grupo não-clínico. As cotas globais e verbais dos dois grupos foram significativamente superiores nas situações de fazer crítica do que de receber crítica. 0 grupo não-clínico foi mais assertivo frente ao interlocutor masculino, mas os pacientes não variaram em função do gênero do interlocutor. 0 conteúdo verbal contribuiu mais para a impressão global de assertividade e, em segundo lugar, os componentes não-verbais. As cotas globais correlacionaram significativamente com comportamentos específicos verbais e não-verbais, medidos por observadores independentes.
\end{abstract}

Palavraschave. Assertividade; psicóticos; reinserção social; desinstitucionalização; desempenho de papéis.

\section{Social Integration of Psychotics: Global Rating of Assertive Behavior in Situations of Making and Receiving Criticism}

\begin{abstract}
The degree of assertiveness of 35 psychotics was evaluated compared to 35 subjects of a non-clinical group, in terms of 5-point Likert rating scales, in situations of making and receiving criticism. Two trained judges observed and rated the subject's behavior in four roleplay videotaped situations. Types of situations and gender of partners were varied. The results showed that patients had a significant deficit in global, verbal and non-verbal ratings of assertiveness, compared to the non-clinical group. Both groups had significant better global and verbal ratings in situations where they were required to critize their partners, compared to situations were they were criticized. Non-clinical group was more assertive with male partners, but patients did not varied their assertiveness with variation in partners'gender. Verbal behavior contributed more than non-verbal behavior to the global impression of assertivenees. Global ratings had significant correlations with specific behavior components measured by independent observers.

Keywords: Assertiveness; rating scales; psychotics; roleplay; social integration.
\end{abstract}

O comportamento assertivo constitui uma classe particular das habilidades sociais, que se refere à capacidade do indivíduo de se afirmar em interações sociais, defender seus direitos, expressar suas opiniões, sentimentos, necessidades e insatisfações e solicitar mudanças de comportamento das outras pessoas, sem desrespeitar os direitosdos outros. Envolveigualmenteaspectosnão-verbais, tais como falar em um tom de voz claro e audível, olhar o interlocutor durantea conversa, sem desviar demais o olhar, falar o tempo necessário para expor sua opinião (Z. A P. Del Prette \& A. Del Prette, 1999; Gambrill, 1978; Lange \& Jakubowski, 1976). O comportamento assertivo énecessário

\footnotetext{
${ }^{1}$ Endereço para correspondência: Departamento de Psicologia - UFRJ, Praça Dom Helvécio, 74, 36300-000, São João del Rei, MG. E-mail: bandeira@ufrj.edu.br

${ }^{2}$ Esta pesquisa foi financiada pela FAPEMIG e pelo CNPq.

${ }^{3}$ Agradecemos ao prof. João Domingos Scalon pela consultoria para análise de dados. Agradecemos à Jucely Cardoso, psicóloga, pela sua participação na observação e cotação dos comportamentos assertivos.
}

em diversas interações sociais que ocorrem nas situações cotidianas e contribui para o desenvolvimento das relações interpessoais, para a capacidade de enfrentamento e resolução de problemas interpessoais, melhorando 0 funcionamento social e a qualidade de vida das pessoas.

No caso particular dos pacientes psicóticos, especialmente 0 esquizofrênico, sua vulnerabilidade às situações estressantes (Zubin \& Spring, 1977) e seu déficit de habilidades sociais e de comportamento assertivo (Bellack, Morrison, Mueser, Wade \& Sayers, 1990; Mueser, Bellack, Douglas \& Morrison, 1991; Mueser, Bellack, Randall, Morrison \& Wade, 1990; Patterson, Moscona, McKibbin, Davidson \& Jeste, 2001) dificultam o enfrentamento de situações interpessoais problemáticas que ocorrem no diaa-dia, elevam o nível deestresse destes pacientesecontribuem para a recorrência desintomasere hospitalizações freqüentes. Estas dificuldades dos pacientes psiquiátricos colocam em risco o seu funcionamento social na comunidade, interferindo com o processo de sua reinserção social. 
Pesquisas realizadas em nosso meio constataram igualmente a presença de déficits de habilidades sociais em uma amostra brasileira de pacientes psicóticos desinstitucionalizados, comparativamente a um grupo de referência não clínico (Bandeira \& Tremblay, 1998; Bandeira, Cardoso, Fernandes, Resende \& Santos, 1998).

Tendo em vista esta dificuldade dos pacientes em lidar com situações interpessoais, a aprendizagem dehabilidades sociais básicas e especialmente dos comportamentos assertivos tem sido considerada como um fator de proteção para os pacientes, de modo a diminuir o impacto dos eventos estressantes (Liberman \& cols., 1993). Programas detreinamento dehabilidades sociais têm incluído o ensino de comportamentos assertivos e de resolução de problemas em situações que requerem, por exemplo, o comportamento dos pacientes de recusar um pedido ou oferta que não lhes convém, assim como solicitar mudança do comportamento indesejável de uma outra pessoa (Wallace, Liberman, Mackain, Blackwell \& Eckman, 1992). O treinamento das habilidades sociais e do comportamento assertivo tem sido freqüentemente utilizado nos programas de reabilitação psiquiátrica, mostrando-se eficaz parafavorecer a reinserção social dos pacientes, uma vez que o número e a gravidade das rehospitalizações dos doentes mentais desinstitucionalizadosé menor quando o nível decompetência social dos pacientes é mais elevado (Bellack, Turner, Hersen \& Kazdin, 1986; Hogart \& cols., 1991; Mueser, Wallace \& Liberman, 1995).

O estudo do comportamento assertivo de pacientes psiquiátricos tem sido realizado principalmente a partir da observação sistemática do comportamento dos sujeitos em interações sociais, através de desempenho de papéis, em situações de asserção positiva e negativa (Bellack, 1983; Bellack \& cols., 1990; Mueser \& cols., 1990). As situações de asserção negativa são particularmente pertinentes para o estudo da assertividade depacientes psiquiátricos, tendo em vista sua dificuldade particular em lidar com 0 enfrentamento de situações de conflito interpessoal e as consequências desta dificuldade para a reinserção social destes pacientes (Cyr, Hodgins, Gaston \& Viens, 1990). Tremblay (1992) destaca, em particular, as situações defazer e receber crítica, que discriminaram significativamente 0 grupo dos pacientes do grupo não-clínico, em seu estudo. No presente trabalho, serão focalizadas estas situações de asserção negativa, de fazer e receber críticas.

As medidas de desempenho de papéis tem apresentado maior validade para a população-alvo de pacientes psiquiátricos, em termos devalidadepreditiva, discriminante e concomitante, assim como fidedignidade inter e intraavaliadores (Bellack \& cols., 1990; Mueser \& cols., 1990; Eisler, Hersen, Miller \& Blanchard, 1975; Mueser \& cols.,
1991; Merluzzi \& Biever, 1987). Este tipo de avaliação requer uma metodologia que se baseia em procedimentos rigorosos de observação sistemática para coleta de dados, que são necessários para se obter medidas válidas e fidedignas, a partir dos dados coletados pelos observadores (Bandeira, 1999, 2002; Bellack 1983). Além disso, o estudo do comportamento assertivo e das habilidades sociais, em geral, requer uma avaliação em diferentes tipos de situação, tendo em vista sua especificidade situacional, pois se trata de desempenho e não de traço (Caballo, 1996; Z. A. P. Del Prette \& A. Del Prette, 1999; Gambrill, 1978). No presente trabalho, será utilizada a metodologia de observação sistemática do comportamento e as variações de demanda da situação e de gênero do interlocutor ao se avaliar o grau de assertividade dos sujeitos.

Uma pesquisa realizada em nosso meio (Bandeira, Machado \& Pereira, 2002) analisou os aspectos moleculares do comportamento assertivo de pacientes psicóticos. Constatou-se que os pacientes apresentavam déficits em componentes específicos da assertividade: eles falavam menos tempo durante as interações sociais estudadas, com um volume de voz mais baixo, uma entonação de voz menos expressiva, além de apresentarem maior freqüência e duração de silêncios em resposta às falas do interlocutor. Estes resultados confirmaram dados de pesquisas feitas em outros contextos culturais (Bellack \& cols., 1990; Patterson \& cols., 2001; Tremblay, 1992).

Apesar da relevância clínica de se fazer uma análise sistemática dos aspectos moleculares do comportamento assertivo, há algumas vantagens em se avaliar, por outro lado, o grau de assertividade de pacientes psiquiátricos através de medidas globais ou cotas atribuídas aos sujeitos por observadores treinados, em termos da impressão global de assertividade que eles veiculam nas interações sociais. Segundo Farrell, Rabinowitz, Wallander e Curran (1985), medidas globais de assertividade são úteis porque fornecem uma estimativa do impacto que as pessoas podem provocar nos outros, duranteas suasinteracõoes sociais. Além disso, as medidas globais representam uma síntese de julgamentos complexos a respeito da integração, da seqüência e da adequacão temporal dos componentes específicos da assertividade, assim como de sua congruência com as demandas do contexto situacional, o que não podeser avaliado através de medidas moleculares (Farrell \& cols., 1985).

Entretanto, medidas globais devem ser ancoradas por critérios específicos de comportamentos, para evitar que os observadores focalizem em comportamentos diferentes, 0 que provocaria inconsistências nas avaliações (Millbrook \& Farrell, 1986). Medidas globais e moleculares do comportamento se complementam, possibilitando uma avaliação mais completa do desempenho dos pacientes. 
Algumas pesquisas têm mostrado que estas duas medidas estão correlacionadas. Por exemplo, Millbrook e Farrell (1986) encontraram quea cota global decompetência social, feita com referentes comportamentais, correlacionava diretamente com a duração da fala e do contato visual e inversamente com o número de silêncios. Penn, Mueser, Doonan eNishith (1995) encontraram igualmentecorrelações significativas entre cotas globais de habilidades sociais e componentes específicos do comportamento.

Em nosso meio, não foram encontradas pesquisas avaliando a impressão global de assertividade veiculada por pacientes psiquiátricos em interações sociais, através de desempenho de papéis e suas relações com as medidas moleculares do comportamento. $O$ presente trabalho visa preencher esta lacuna.

\section{Método}

\section{Participantes}

A amostra se constituiu de 70 participantes do sexo masculino, de nível sócio-econômico baixo, da cidade de São João Del Rei e região, envolvendo dois grupos, descritos abaixo:

Grupo díniø: incluiu 35 pacientes psiquiátricos, com idade média de 39,4 anos ( $\mathrm{dp}=3,3$ ), que moravam com suas famílias e que foram selecionados de arquivos de hospitais psiquiátricos públicos (Hospital Psiquiátrico da FHEMIG de Barbacena e Hospital Paulo Menicucci de Lavras). Estes pacientes haviam sido diagnosticados como psicóticos pelos psiquiatras dos hospitais (CID 295 e 298). Foram excluídos os indivíduos que apresentavam retardo mental, distúrbios orgânicos ou quetiveram dificuldades de entender asinstruções dadas duranteas sessões experimentais.

Gruponão-dínio: incluiu 35 sujeitossem históriapsiquiátrica, com idade média de 37,37 anos ( $\mathrm{dp}=11,19)$, que habitavam na mesma região geográfica dospacientes, constituindo assim um grupo de referência dos pacientes na comunidade.

\section{Procedimento}

Situaçoessodiais

A assertividade dos sujeitos foi avaliada através do desempenho depapéis (roleplay) em quatro situações sociais de asserção negativa, de fazer e receber críticas, que representavam interações sociais cotidianas entre membros de uma família, gravadas em vídeo. As situações utilizadas aqui são as mesmas adotadas no estudo de Bandeira e colaboradores (2002). Foram utilizados dois tipos de situação: no primeiro, o participantedevia fazer uma crítica ao interlocutor, expressando claramentesuainsatisfação com o seu comportamento indesejável e solicitando uma mudança deste comportamento. No segundo tipo de situação, o participante devia reagir a uma crítica feita pelo interlocutor, reconhecendo sua responsabilidade, porém afirmando ejustificando sua necessidade naquela situação e propondo uma solução para o problema, que satisfizesse a sua necessidade, porém sem desrespeitar a do outro. Para cada tipo de situação, variou-se o gênero do interlocutor. O sujeitos interagiam com interlocutores previamente treinados para este fim, os quais utilizavam réplicas múltiplas padronizadas, porém flexíveis, que favoreciam uma maior naturalidade nas interações sociais (Bandeira \& Tremblay, 1998; Bandeira \& cols., 1998).

\section{Treinamento dosjuízes}

Dois juízes foram treinados para fazer a observação do desempenho dos sujeitos, avaliando a assertividade verbal, não-verbal e global, em uma escala tipo Likert de 5 pontos ou cotas. O treinamento foi realizado diariamentedurante 3 meses, utilizando-se de gravações de sujeitos que não participavam da pesquisa.

Nas sessões diárias de treinamento, cada observador observava sozinho um participante por dia, por 1 hora aproximadamente. Em seguida, os observadores faziam uma sessão de discussão, calculando a porcentagem de acordos e desacordos obtidos. Os desacordos eram discutidos com o pesquisador, a cena era revista e buscavase então identificar as causas dos desacordos, visando estabelecer critérios comuns de atribuição das cotas pelos dois observadores. $\mathrm{O}$ treinamento foi encerrado quando os dois observadores atingiram $85 \%$ de acordo em suas observações.

\section{Coleta dedados}

Após o treinamento, iniciou-se a coleta de dados. Os observadores estavam "cegos" quanto ao grupo a que pertenciam os sujeitos, a fim de evitar o viés do observador na cotação dos comportamentos. Foi observado um participante por dia, para evitar que o cansaço dos observadores diminuísse sua capacidade de atenção e concentração. As sessões deobservação eram diáriasetinham a duração média de 4 horas. Cada juiz observava os vídeos independentemente um do outro. A coleta de dados teve a duração de 5 meses.

Durante as sessões de observação, cada observador avaliavacada umadas quatro situações sociaisseparadamente. Para cada situação, avaliava-se primeiro o grau de assertividade verbal, em seguida observava-se novamente a mesma situação para avaliar o grau de assertividade nãoverbal e, por fim, avaliava-se a assertividade global. Estes dados eram posteriormente utilizados para os cálculos de correlação entre os escores dos dois juízes, necessários à avaliação dafidedignidadedasmedidasou acordo interjuízes. 
Após a observação de um dado sujeito, os dois juízes calculavam a porcentagem de acordos obtidos entre eles, discutiam a respeito dos desacordos e chegavam a um consenso. $\mathrm{O}$ cálculo da porcentagem de acordos era feito diariamente, a fim de queestefeedbadk contínuo contribuísse para manter um alto padrão de fidedignidade interobservadores.

Para padronizar a avaliação do comportamento, os observadores usavam uma folha de definições de assertividade correspondentes a cada um dos 5 pontos da escala tipo Likert. Além disso, eles anotavam os dados observados em três folhas de Registro deComportamentos, separadamentepara asmedidas verbais, não-verbaiseglobais de assertividade. Cada observador anotava também os comportamentos nos quais ele se baseava para atribuir os pontos. Esteprocedimento visava assegurar queum mesmo ponto dado pelos dois observadores correspondesse aos mesmos comportamentos observados. Em caso de desacordo, seria mais fácil identificar suas causas, contribuindo assim para a validade e fidedignidade das medidas.

\section{D escrição das Escalas deA ssertividade}

As medidas de cotas globais de assertividade utilizadas no presente trabalho foram definidas a partir de referentes comportamentaisespecíficos, nos quaisosjuízes se baseavam para avaliar os comportamentos. Este tipo de escala é recomendado para o estudo observacional do comportamento, a fim de favorecer a fidedignidade das medidas empregadas, na maioria dos estudos com pacientes psiquiátricos (Bellack, 1983; Millbrook \& Farrell, 1986).

Foi utilizada uma escala tipo Likert de 5 pontos ou cotas mutuamente exclusivas (Bellack \& cols., 1990), onde 1 indicava que o participanteera muito inassertivo, 2 Inassertivo, 3 mediamenteassertivo, 4 assertivo e 5 muito assertivo. Havia três escalas como esta para a avaliação da assertividade verbal, não-verbal e global, que serão descritas abaixo.

Escala verbal: A assertividade verbal era avaliada em cada situação social, em função do desempenho de dois comportamentos verbais assertivos: 1) expressar necessidade ou insatisfação e 2) solicitar mudança de comportamento do interlocutor ou propor uma solução para o problema discutido. 0 desempenho verbal dos participantes era avaliado em termos da presença ou não destes dois comportamentos, da sua adequação e congruência com a situação, do grau deargumentação com o interlocutor, assim como da fluência da fala. Esta avaliação era feita a partir de uma escala de 1 a 5, onde 1 indicava um desempenho muito inadequado pela ausência dos dois comportamentos verbais e 5 indicava um desempenho muito adequado de ambos os comportamentos verbais assertivos.
Escala não-verbal : Para avaliar a assertividadenão-verbal, os juízes observavam a adequação do desempenho dos participantes, em termos dos seguintes referentes comportamentais: latência adequada, nem lenta demais nem curta demais, de forma a não interromper a fala do interlocutor; duração da fala suficientepara expor o assunto; contato visual direto com o interlocutor, porém sem fixálo demais; volume da voz claramente audível; ausência de silêncios em resposta ao interlocutor; ausência de perturbações da fala, tais como hesitações e repetições de sílabas ou palavras; afeto modulado e congruente com a situação; entonação da voz modulada, expressiva. Osjuízes observavam estes comportamentos, levando em conta sua freqüência, duração, intensidade, assim como a integração entre eles, sua congruência com a situação estudada e seu impacto positivo ou negativo no desempenho do participante. Esta avaliação era feita através de uma escala de 1 a 5, onde 1 indicava um desempenho muito inassertivo pela ausência da maioria dos componentes citados acima ou a presença de componentes excessivamenteinadequados e5 indicava um desempenho muito assertivo, pela presença da maioria destes componentes e sua adequação, tal como indicado acima.

Escala global: Os juízes avaliavam o desempenho dos sujeitos, levando em consideração a impressão geral que os participantes veiculavam em sua interação com 0 interlocutor, em termos da defesa de seus direitos, de sua afirmação diante do outro e em termos de terem atingido ou não o objetivo da situação. Os juízes se baseavam tanto no que havia sido observado de seu comportamento verbal, quanto não-verbal. Pesava-se todos os componentes, assim como sua integração, avaliando-se sua importância e seu impacto naimpressão geral deassertividadedo sujeito. Estas avaliações eram feitas através de uma escala de 1 a 5, onde 1 indicava um desempenho muito inassertivo, submisso, sem defesa de suas necessidades ou insatisfações e 5 indicava um desempenho muito assertivo, onde o participante seafirmava convincentementefrenteao interlocutor.

Análisedos Dados

Comparação entre grupos: Após a atribuição de cotas para todos os sujeitos, procedeu-se à análise dos dados, comparando-se o grupo clínico com o grupo não-clínico, através da Análise de Variância (ANOVA).

Além disso, dividiu-se a amostra de sujeitos em dois grupos, em função de seus escores globais de assertividade: um grupo Menos Assertivo e um grupo Mais Assertivo. 0 grupo Menos Assertivo ( $\mathrm{N}=13$ ) incluiu os participantes que haviam obtido os escores mais baixos da amostra (1,00 a 1,25), dentre os quais 12 eram pacientes. $O$ grupo Mais Assertivo $(\mathrm{N}=12)$ incluiu os participantes que haviam recebido os escores mais elevados da amostra $(2,75$ a 3,00), 
dentre os quais 10 eram participantes da população geral. Estes dois grupos foram comparados, através da Análise de Variância, para se identificar os comportamentos verbais e não-verbais específicos que os diferenciavam significativamente.

Para isto, foram utilizadas as medidas de comportamentos específicos que haviam sido tomadas previamente por observadores independentes, os quais desconheciam as cotas globais. Estas medidas haviam sido tomadas no contexto de uma pesquisa anterior, realizada a partir das mesmas gravações dos participantes da presente pesquisa e a sua coleta de dados está detalhadamentedescrita em outro artigo (Bandeira \& cols., 2002). Estas medidas serão definidas abaixo, mas sua coleta de dadosnão será descrita novamente aqui, para evitar estender desnecessariamente este texto.

Comparação das CotasGlobaiscom medidascomportamentais espeáficas Parainvestigar seaimpressão global deassertividade, medidaatravés decotas, estava relacionada com afreqüência eduração decomportamentosespecíficos dos participantes, foi feita uma análise correlacional de Pearson entre estes dois tipos de medida, global e específica. Para isto, foram utilizadas as medidas de comportamentos específicos definidas abaixo.

Os componentesnão-verbaisespećficosutilizadosna análise correlacional foram: 1) Proporção de duração da fala: tempo de duração da fala do participante dividido pelo tempo total de duração da situação; 2) Duração dos silêncios: soma total dos intervalos de tempo em que o participante permaneceu calado em resposta às falas do interlocutor. Cada intervalo de silêncio do participante foi contado a partir do final de uma fala do interlocutor até a sua fala seguinte. 3) Proporção das alterações da fala: número dealterações da fala do participantedividido pelo tempo total em que este falou durante a situação. Foram consideradas como alterações da fala: gagueira, pausas de mais de três segundos, repetições de frases ou de palavras e expressões não-funcionais entre as frases, tais como ahh, ehn uhn, etc. 4) Freqüência dos silêncios: número de vezes em que o participantepermanecia calado após as falas do interlocutor, portanto não respondendo às suasintervenções; 5) Proporção do contato visual: tempo de duração do contato visual do participante com 0 interlocutor, dividido pelo tempo de duração da situação; 6) Duração daslatências: somatotal dosintervalos de tempo decorridos entre cada fala do interlocutor e o início de cada fala do participante sem respostaao interlocutor; 7) Volume da voz, definido como o grau deintensidade davoz, medido através de uma escala tipo Likert de 5 pontos indicando: 1=muito baixo, 2=baixo, 3=médio, 4=alto, 5=muito alto; 8) Afeto apropriado: 0 participante devia veicular emoção ao interagir com o interlocutor e esta emoção devia ser congruente com a situação, o que era medido a partir da seguinteescala: 1 =muitoinapropriado, $2=$ =inapropriado, $3=$ =médio, 4= apropriado, 5=muito apropriado; 9) Entonação da voz: modulação do tom de voz que dá ênfase ao conteúdo da fala, avaliado segundo a seguinte escala: $1=$ muito inexpressiva, 2= inexpressiva, 3= média, 4=expressiva, 5=muito expressiva (Bandeira \& cols., 2002).

Os componentes verbais espećficos utilizados na análise correlacional foram: 1) Freqüência do comportamento de expressar necessidade ou insatisfação; 2) Freqüência do comportamento de propor uma solução ou pedir uma mudança de comportamento; 3) Conteúdo Verbal Total: soma dos dois componentes verbais definidos acima, apresentados por cada participante no total das quatro situações, podendo variar entre 0 e 8.

\section{Fidedignidade das Medidas}

A avaliação da fidedignidade das medidas foi feita a partir de duas análises: a porcentagem de acordos obtidos entre os juízes e a análise correlacional de Pearson entre os escores dos dois juízes. Estas análises foram feitas a partir das medidas dos dois observadores colhidas anteriormente às reuniões diárias de consenso.

O cálculo da porcentagem de acordos interjuízes era feito diariamente e incluiu os dados obtidos com todos os 70 participantes, a fim deseobter uma estimativa maisprecisa da fidedignidade da medida. $\mathrm{O}$ valor médio obtido para as porcentagens de acordos interjuízes foi $92,59 \%$, considerando-se todas as medidas. Para a cota global, a porcentagem de acordo foi 93,57\%, para a cota verbal foi 92,86\% e para a cota não-verbal foi 86,79\%.

Para se fazer a análise correlacional, foi sorteada uma amostra de $50 \%$ dos participantes da pesquisa $(n=35)$. Os resultados indicaram que o acordo interjuízes foi elevado, para os escores de assertividade global $(r=0,99 ; \mathrm{p} \varangle 0,001)$, não-verbal ( $r=0,98 ; p \varangle 0,001)$ e verbal $(r=0,96, p \varangle 0,001)$.

$\mathrm{O}$ alto grau de fidedignidade obtido se deve provavelmente a certas características do procedimento adotado, tais como o treinamento prolongado dosjuízes, 0 uso de critérios específicos de observação e avaliação, a utilização de referentes comportamentais para as cotas e 0 fato de se observar apenas um participante por dia, demodo a favorecer a concentração dosjuízes eminimizar o cansaço. Além disso, o cálculo diário da porcentagem de acordos obtidos pelos dois juízes durante todo o período de coleta de dados servia como fedbadk eincentivo diários para o seu desempenho na observação dos participantes.

\section{Resultados}

A equivalência dos dois grupos havia sido verificada previamente, com relação às variáveis idade, estado civil, renda familiar e per-capita, tipo de residência, nível de 
escolaridade e número de repetições escolares. Não havia diferenças significativas entre os grupos com relação a estas variáveis, o quepossibilita uma maior validadeinterna da pesquisa e uma maior confiabilidade dos resultados (Bandeira \& Tremblay, 1998).

\section{Diferenças entre os grupos clínico e não- clínico quanto ao grau de assertividade}

Os resultados obtidos mostraram que os pacientes apresentavam um déficit de assertividade em relação ao seu grupo de referência, no conjunto das quatro situações. A Tabela 1 mostra as médias e os desvios-padrão das cotas globais de ambos os grupos. Pode-se observar uma diferença significativa entre os grupos com relação à assertividade global $(F=25,82 ; p<0,001)$, verbal $(F=33,27$; $\mathrm{p} \varangle 0,001)$ e não-verbal $(\mathrm{F}=5,83 ; \mathrm{p} \varangle 0,05)$.

Procurou-se verificar igualmente qual dimensão, verbal ou não-verbal, do comportamento dos participantes contribuía mais para a impressão global de assertividade. Para isto, foi feita uma análise de correlação de Pearson entre os três tipos de cotas atribuídas aos participantes. Os resultadosmostraram queaimpressão global deassertividade se baseava mais nos aspectos verbais do comportamento do participante, pois foi obtida uma correlação mais elevada entre a cota global e a cota verbal $(\mathrm{r}=0,94 ; \mathrm{p} \varangle 0,001)$ do que entre a cota global e a cota não-verbal $(r=0,73 ; p \varangle 0,001)$.

\section{Diferenças de assertividade em função de mudanças situacionais}

Tomando-se a amostra dos sujeitos como um todo, os resultados mostraram que o comportamento assertivo dos sujeitosvariou em função dostipos de situaçõesinterpessoais. Esta variabilidade, verificada através da análise de variância de medidas repetidas (MANOVA), ocorreu tanto no que se refere à assertividade global $(\mathrm{F}=32,16 ; \mathrm{p} \varangle 0,001)$ quanto à assertividade verbal $(\mathrm{F}=56,22 ; \mathrm{p} \varangle 0,001)$. Entretanto, no queserefereà assertividadenão-verbal, não houve diferença significativa de uma situação para outra $(\mathrm{F}=1,39 ; \mathrm{p}=0,25)$. As cotas não-verbais de assertividade foram, portanto, menos sensíveis aos efeitos das mudanças experimentais.

Foi feitauma análise estatística através do testet deStudent, para amostras pareadas, visando identificar diferenças de assertividade de um mesmo grupo face a mudanças no tipo de situação (fazer ou receber uma crítica) e no gênero do interlocutor. Estas análises, descritas abaixo, mostraram menor variabilidade no comportamento dos pacientes.

\section{Diferenças de assertividade frente a mudanças no tipo de demanda da situação}

Ambos os grupos de sujeitos foram mais assertivos ao fazer uma crítica do que ao receber uma crítica. As Tabelas 2 e 3 mostram as médias e os desvios-padrão das cotas atribuídas aos dois grupos de participantes, nestes dois tipos de situação. Pode-se observar que os participantes do grupo dínico reagiram de forma significativamente diferente em relação aos tipos de situação, quanto ao grau deassertividade global $(t=-5,26 ; p<0,001)$ e verbal $(t=-7,41 ; p<0,001)$, mas não quanto ao grau de assertividade não-verbal $(\mathrm{t}=$ $0,42 ; \mathrm{p}=0,68)$.

O mesmo ocorreu com os participantes do grupo nãodíniø. Eles reagiram de forma significativamente diferente

Tabela 1

MédiaseDesviospadrão da AssertividadeGlobal, Verbal eNão-verbal dosGnuposClíniø eNão-díniø, nasQuatro Situaçoes

\begin{tabular}{lllllll}
\hline Grupos & \multicolumn{4}{c}{ Global } & \multicolumn{2}{c}{ Assertividade } \\
& $\mathrm{m}$ & $\mathrm{dp}$ & $\mathrm{m}$ & $\mathrm{dp}$ & $\mathrm{m}$ & $\mathrm{d}$ \\
& 1,73 & 0,58 & 2,17 & 0,73 & 1,61 & 0,63 \\
Clínico & $1,97^{* *}$ & 0,62 & $2,35^{* * *}$ & 0,41 & $3,06^{* * *}$ & 0,54 \\
Não-clínico & 0,62 & &
\end{tabular}

$* * p \varangle 0,05 ; * * * p<0,001$

Tabela 2

MédiaseD esvios- padrão (dp) do Grau deAssertividadeGlobal, Verbal eNão-verbal do Grupo Clínio por Tipo de Situação

\begin{tabular}{lcccccc}
\hline $\begin{array}{l}\text { Tipos de } \\
\text { situação }\end{array}$ & \multicolumn{4}{c}{ Global } & \multicolumn{2}{c}{ Assertividade } \\
& $\mathrm{m}$ & $\mathrm{dp}$ & $\mathrm{m}$ & $\mathrm{dp}$ & \multicolumn{2}{c}{ Não-verbal } \\
\hline \multirow{2}{*}{$\begin{array}{l}\text { Receber uma crítica } \\
\text { Fazer uma crítica }\end{array}$} & $1,41^{* * * *}$ & 0,53 & 1,55 & 0,59 & 1,63 & $\mathrm{dp}$ \\
& $2,06^{* *}$ & 0,81 & 2,78 & 1,10 & 1,60 & 0,66 \\
\hline
\end{tabular}


frente aos dois tipos de situação, em relação ao grau de assertividade global $(t=-6,78 ; p<0,001)$ e verbal $(t=-9,91$; $\mathrm{p}<0,001)$, mas não de assertividade não-verbal $(\mathrm{t}=-1,99$; $\mathrm{p}=0,058)$.

\section{Diferenças de assertividade frente a mudanças no gênero dos interlocutores}

Os pacientes não variaram em sua assertividade diante dosinterlocutores do sexo masculino ou feminino, enquanto que seu grupo de referência variou, se mostrando mais assertivo diante do interlocutor do sexo masculino. O bservou-se portanto, uma menor variabilidade no comportamento dos pacientes frente a estas mudanças situacionais.

As Tabelas 4 e 5 mostram as médias e os desvios-padrão das cotas de assertividade atribuídas aos dois grupos frente ao interlocutor do sexo feminino edo sexo masculino. Podese observar que, no caso do grupo dínico, a assertividade dos pacientes não variou significativamente diante de interlocutores do sexo masculino ou feminino, tanto no que se refere à assertividade global $(t=-0,15 ; \mathrm{p}=0,88)$, quanto à assertividade verbal $(t=-1,84 ; p=0,07)$ e não-verbal $(t=$ 0,$64 ; p=0,52$ ).

Já o grupo não-díniøapresentou uma diferença significativa frente a mudanças no gênero do interlocutor, no que se refere à assertividade global $(\mathrm{t}=-2,74 ; \mathrm{p}<0,05)$ e verbal $(\mathrm{t}=$ $-3,36 ; p<0,05)$, tendo sido mais assertivo diante do interlocutor do sexo masculino. Quanto à assertividadenãoverbal, não houvevariação frenteaosinterlocutores do sexo masculino ou feminino $(t=1,19 ; \mathrm{p}=0,24)$, mostrando uma maior constância das cotas não-verbais.

Tabela 3

Médiase Desvios-padrão do Grau deA ssertividadeGlobal, Verbal e Não-verbal do Grupo Não-dínico por Tipo deSituação

\begin{tabular}{lcccccc}
\hline $\begin{array}{l}\text { Tipos de } \\
\text { situação }\end{array}$ & \multicolumn{2}{c}{ Global } & \multicolumn{2}{c}{ Assertividade } \\
& $\mathrm{m}$ & $\mathrm{dp}$ & $\mathrm{m}$ & $\mathrm{dp}$ & \multicolumn{2}{c}{ Não-verbal } \\
\hline \multirow{2}{*}{$\begin{array}{l}\text { Receber uma crítica } \\
\text { Fazer uma crítica }\end{array}$} & 1,92 & 0,63 & 2,30 & 0,88 & $\mathrm{~m}$ & $\mathrm{dp}$ \\
& $2,77 * * *$ & 0,46 & $3,82^{* * *}$ & 0,54 & 0,70 \\
**** & & & & 2,08 & 0,71 \\
\hline
\end{tabular}

Tabela 4

Médiase D esvios padrão do Grau deA ssertividadeGlobal, Verbal eNão-verbal do Grupo Clíniø em Função do Gênero do Interloautor

\begin{tabular}{lccccccc}
\hline $\begin{array}{l}\text { Gênero do } \\
\text { interlocutor }\end{array}$ & \multicolumn{4}{c}{ Global } & \multicolumn{2}{c}{ Assertividade } & \multicolumn{2}{c}{ Verbal } & \multicolumn{2}{c}{ Não-verbal } \\
\hline \multirow{2}{*}{ Sexo feminino } & $\mathrm{m}$ & $\mathrm{dp}$ & $\mathrm{m}$ & $\mathrm{dp}$ & $\mathrm{m}$ & $\mathrm{dp}$ \\
Sexo masculino & 1,77 & 0,63 & 2,04 & 0,81 & 1,64 & 0,69 \\
& 1,74 & 0,66 & 2,30 & 0,88 & 1,58 & 0,68 \\
\hline
\end{tabular}

Tabela 5

MédiaseD esvios- padrão do Grau deAssertividadeGlobal, Verbal eNão-verbal do Grupo Clíniø em Função do Gênero do Interloautor

\begin{tabular}{lcccccc}
\hline $\begin{array}{l}\text { Gênero do } \\
\text { interlocutor }\end{array}$ & \multicolumn{2}{c}{ Global } & \multicolumn{2}{c}{ Assertividade } \\
Verbal & \multicolumn{2}{c}{ Não-verbal } \\
\hline \multirow{2}{*}{ Sexo feminino } & $\mathrm{m}$ & $\mathrm{dp}$ & $\mathrm{m}$ & $\mathrm{dp}$ & $\mathrm{m}$ & $\mathrm{dp}$ \\
Sexo masculino & 2,21 & 0,53 & 280 & 0,73 & 2,03 & 0,70 \\
& $2,48^{* *}$ & 0,48 & $3,33^{* * *}$ & 0,68 & 1,93 & 0,64 \\
\hline
\end{tabular}

$* * p<0,05$

$* * * \mathrm{p}<0,001$ 


\section{Relações entre a Cota Global e as Medidas Moleculares da Assertividade}

A impressão de que a pessoa está sendo assertiva em uma interação social depende das diversas dimensões de seu comportamento frente ao interlocutor. As análises abaixo exploram estas relações, tentando identificar quais aspectos específicos estavam mais relacionados à impressão global de assertividade.

Cota global eo conjunto detodosos componenteseppeáficos Foi feita uma análise correlacional de Pearson entre a cota global e os comportamentos específicos verbais e nãoverbais, definidos acima. O s resultados mostraram que a impressão global de assertividade veiculada pelos sujeitos foi determinada, em primeiro lugar, pelo conteúdo verbal da fala dos sujeitos, pois obteve-se uma correlação mais elevada com esta variável $(r=0,89 ; p \varangle 0,001)$ do que com os componentes não-verbais do desempenho dos sujeitos $(r=0,28 ; p \varangle 0,05$ a $r=0,78 ; p \varangle 0,001)$.

Cota global eos componentes verbais da assertividade Para verificar qual dos dois comportamentos verbais estudados contribuiu mais para a impressão global de assertividade, foi feita uma análise correlacional de Pearson entre estas medidas. Os resultados mostraram uma correlação mais elevada entrea cota global ea freqüência do comportamento de propor uma solução ou pedir uma mudança de comportamento do interlocutor $(r=0,76 ; \mathrm{p} \varangle 0,001)$ do que a correlação entre a cota global e a frequiência do comportamento de expressar insatisfação ou necessidade $(r=0,57 ; p \varangle 0,001)$. Ou seja, o que contribuiu mais para a impressão global de assertividade foi o fato da pessoa solicitar uma mudança de comportamento do interlocutor ou propor uma solução para resolver o problema dos dois.

Cota global ecomponentesnão-verbaisda assertividade Para verificar a ontribuição relativa unicamentedoscomponentes não-verbais para a impressão global de assertividade, foi feita uma análise correlacional de Pearson entre estes dois tipos devariáveis, excluindo-se portanto os aspectos verbais. Os resultados mostraram que quanto maior era o grau de assertividade global veiculada pelos sujeitos, maior era a proporção da duração da sua fala $(r=0,50 ; \mathrm{p} \varangle 0,001)$, menor era a frequência dos seus silêncios $(r=-0,52 ; p \varangle 0,001)$ e menor era a duração dos seus silêncios em resposta às falas do interlocutor $(r=0,52 ; p \varangle 0,001)$, menor era a sua latência ao responder ao interlocutor $(\mathrm{r}=-0,44 ; \mathrm{p}<0,001)$, maior era 0 volume da sua voz $(r=0,53 ; p \varangle 0,001)$, maior era 0 grau de adequação do afeto veiculado por ele $(r=0,52 ; p \varangle 0,001)$, maior era a expressividade da entonação da sua voz $(\mathrm{r}=0,68$; $\mathrm{p} \varangle(, 001)$ e menor a proporção de alterações da sua fala $(r=-0,29 ; p<0,05)$.

\section{Adequação do Afeto e as Cotas Verbaise Não-verbais}

Para verificar qual dimensão, verbal ou não-verbal, contribuía mais para a impressão de adequação do afeto, foi feita uma análise de correlação de Pearson entre as cotas verbais, não-verbais e o grau de adequação do afeto. Obteve-se uma correlação mais elevada entre a adequação do afeto e a cota não-verbal $(r=0,48 ; p \varangle 0,001)$ do que entre a adequação do afeto e a cota verbal $(\mathrm{r}=0,44$; $\mathrm{p}<0,001)$. Estes resultados indicam, portanto, que 0 grau de adequação do afeto foi mais determinado pela impressão que o participante causou ao nível não-verbal.

\section{Diferenças entre os sujeitos Menos Assertivos e Mais Assertivos}

Foram comparados estes dois subgrupos de sujeitos, através de uma análise de variância (ANOVA), utilizandose as medidas de cotas verbais e não-verbais, assim como todas as medidas de comportamentos específicos. A Tabela 6 mostra as médias e desvios-padrão destas medidas para os dois subgrupos Menos Assertivo e Mais Assertivo.

Os resultados mostraram diferenças significativas entre estes dois subgrupos, no que se refere a diversos componentes específicos da assertividade. Os sujeitos do grupo mais assertivo tomavam a palavra por mais tempo $(\mathrm{F}=12,33 ; \mathrm{p}<0,05)$, com um volume de voz mais alto $(F=10,96 ; p \varangle 1,05)$ e uma entonação mais modulada ou expressiva ( $F=43,44 ; p \varangle 0,001$ ), olhando mais tempo para 0 interlocutor durante a interação social $(F=5,33 ; p \varangle 1,05)$ e veiculando emoção mais congruente com a situação $(\mathrm{F}=9,75 ; \mathrm{p}<0,05)$. Eles também respondiam mais prontamente ao interlocutor $(\mathrm{F}=11,57 ; \mathrm{p}<0,05)$ e apresentavam menor freqüência de alterações da fala, tais como gagueira ou repetições inúteis de palavras $(\mathrm{F}=4,32$; $\mathrm{p} \varangle 0,05$ ). Os sujeitos mais assertivos apresentavam uma frequiência menor de silêncios $(F=4,83 ; p \varangle 0,05)$ e uma duração menor de silêncios $(F=5,12 ; p \varangle 0,05)$ em resposta às falas do interlocutor. Os sujeitos mais assertivos comunicavam mais freqüentemente sua insatisfação ou necessidade ( $F=16,44 ; \mathrm{p} \varangle 0,001)$ e pediam mais mudança do comportamento do interlocutor ( $F=73,61 ; p \varangle 0,001$ ). Além disso, eles obtiveram valores mais altos na cota verbal de assertividade ( $F=153,4 ; p \varangle 0,001)$ e na cota não-verbal $(F=99,02 ; p \varangle 1,001)$. Estes resultados mostraram que todos os componentes analisados contribuíram para diferenciar estes dois sub-grupos de participantes.

\section{Discussão}

Os resultados obtidos na presente pesquisa mostraram, em primeiro lugar, que os pacientes apresentaram um déficit significativo de assertividade em relação ao seu 
grupo de referência. Esta dificuldade se manifestou tanto em relação ao conteúdo da fala dos pacientes, quanto aos aspectos não-verbais do seu comportamento nas interações sociais.

Resultados semelhantes, indicando um déficit de habilidades sociais e de assertividade de pacientes psiquiátricos, através da atribuição de cotas globais por observadores, foram observados por diversos autores, em situações de asserção negativa e positiva (Bellack \& cols., 1990; Mueser \& cols., 1990, 1991; Patterson \& cols., 2001; Tremblay, 1992). Mueser ecolaboradores (1991) mostraram queestes déficits são estáveis, semantendo durante o período de um ano do seu estudo. Esta convergência de resultados, obtidosa partir degrupos depacientes deculturas diferentes, indica que as dificuldades de assertividade dos pacientes psiquiátricostranscendem o contexto cultural. O sresultados obtidosno presentetrabalho colocam em destaque, portanto, a necessidade da aprendizagem da assertividade para os pacientes psiquiátricos, em programas de readaptação psicossocial, no nosso contexto.

Em segundo lugar, constatou-se que a impressão global de assertividade dependeu da contribuição de alguns comportamentos específicos verbais e não-verbais. Esta contribuição foi maior do conteúdo da fala, em particular o comportamento de pedir mudança do comportamento do interlocutor ou propor uma solução para a situação, do que dos aspectos não-verbais, confirmando dados de outros pesquisadores (Tremblay, 1992). Segundo Bellack (1983), diversas pesquisas nesta área têm mostrado que o conteúdo da fala constitui freqüentemente o principal componentea contribuir para a impressão global de competência social e, em segundo lugar, o comportamento de olhar.

Por outro lado, os aspectos não-verbais foram também importantes para formar a impressão de assertividade. Por exemplo, o grau de adequação do afeto veiculado pelos sujeitos nas interações sociais dependeu mais dos aspectos não-verbais de seu comportamento, resultado este que tem sido observado em outros estudos, segundo Bellack (1983). Além disso, os principais fatores preditivos de uma impressão global de assertividade foram uma entonação de voz mais expressiva, um maior volume da voz, uma menor freqüência e duração dos silêncios e uma maior adequação do afeto. Em seguida, destacaram-se os seguintes aspectosnão-verbais: uma maior duração da fala, uma maior prontidão para responder e uma menor freqüência de alterações da fala.

Estes resultados confirmam dados de outros autores. Millbrook, Farrell e Curran (1986) também encontraram uma correlação significativa entre a impressão global de competência social medida por cotas e a duração do olhar dos sujeitos em direção ao interlocutor, assim como a duração de sua fala.

Psioologia: Reflexão e Crítica, 2002, 15(3), pp. 665-675
Estes autores observaram que os fatores que mais contribuíam para dar a impressão global de uma pessoa socialmente competente eram uma maior duração da fala do sujeito, maior duração do olhar e menor freqüência de silêncios. Trower (1980) encontrou que a duração da fala foi o componente que mais contribuiu para a cota global de competência social de pacientes psiquiátricos, seguidos da duração do olhar e da freqüência de gestos de apoio à fala. Correlações significativas entre a cota global de habilidades sociais ea adequação de componentes específicos do comportamento foram igualmente encontradas por outros autores (Mueser \& cols., 1991; Penn \& cols., 1995). Esta correlação entre medidas globais e específicas da assertividade atesta a validade das medidas e nos fornecem mais segurança para usá-las em programas de treinamento da assertividade (Merluzzi \& Biever, 1987; Trower, 1980).

A relação entre os aspectos globais e específicos da assertividade ficou evidenciada igualmente ao se comparar o subgrupo mais assertivo com o subgrupo menos assertivo de nossa amostra. Constatou-se que as pessoas mais assertivas, avaliadas em termos das cotas globais, foram capazes de tomar a palavra por mais tempo e de olhar mais tempo para o interlocutor, nas interações sociais. Além disso, elas apresentaram menor freqüência e duração de silêncios e falaram com um tom de voz mais alto, com uma entonação devoz mais expressiva ecom um menor número de alteracõoes da fala do que as pessoas menos assertivas.

Estes resultados confirmaram dados de outros pesquisadores em outros contextos culturais. Por exemplo, Eisler e colaboradores (1975) observaram igualmente que os sujeitos assertivos solicitavam mais mudança de comportamento do interlocutor, falavam por mais tempo e com um volume de voz mais alto, expressavam afeto mais congruente com a situação e respondiam mais rapidamente ao interlocutor, em situações sociais de asserção negativa. Trower (1980) observou estes mesmos resultados ao comparar pacientes classificados como socialmente competentes e incompetentes, com relação ao tempo de fala e à duração do contato visual com 0 interlocutor. Os resultados obtidos no presente trabalho, portanto, confirmam dados de outros pesquisadores, a respeito da correspondência entre medidas globais e moleculares, em diferentes contextos culturais.

Uma outra constatação da presente pesquisa é de que o grau de assertividade global e verbal dos participantes, medido através de cotas, variou em função do tipo de situação social, confirmando assim seu caráter situacional. Ambos os grupos, clínico enão-clínico, se mostraram mais assertivos nas situações de fazer uma crítica do que na situações dereceber uma crítica, sugerindo queestas últimas apresentariam maior dificuldade para os participantes. 
Estes resultados, obtidos através de cotas globais, concordam com os dados encontrados por Bandeira e colaboladores (2002), referentes às medidas moleculares da assertividade, para estes mesmos tipos de situação. Tremblay (1992) observou igualmente maior grau de habilidades sociais em situações de expressar insatisfação do que em situações de receber críticas. Estas diferenças encontradas no grau de assertividade em diferentes tipos de situação constituem uma informação importantepara o planejamento de programas educativos, referentes ao treinamento da assertividade (Bellack, 1983).

Os resultados citados acima indicaram que a avaliação do desempenho depapéisatravésdecotaséum instrumento de medida sensível aos efeitos diferenciais das mudanças introduzidas nas situações sociais, para avaliar o grau de assertividade de pacientes psiquiátricos, o que confirma dados obtidos por outros pesquisadores (Bellack \& cols., 1990; Trower, 1980). Entretanto, a cota de assertividade não-verbal, em particular, não variou facea diferentes tipos de situação ou a mudanças no gênero do interlocutor, mostrando-se portanto uma medida menos sensível aos efeitos estudados. Bellack e colaboradores (1990) encontraram igualmente que a cota não-verbal de competência social apresentou menor variabilidade em função de variações situacionais. Comportamentos nãoverbais podem ser mais difíceis de serem avaliados através de cotas globais, tornando-as assim menos capazes de discriminar diferenças resultantes de mudanças nas situações sociais. Neste caso, medidas moleculares deveriam ser utilizadas concomitantementeàs cotas globais para avaliar o efeito de fatores situacionais em componentes nãoverbais específicos.

A menor variabilidade observada no comportamento dos pacientes em função de mudanças nas situações experimentais, medida através de cotas, confirma dados obtidos através de medidas moleculares da assertividade, em nosso meio (Bandeira \& cols., 2002). Dados de pesquisas obtidos em outros contextos culturais encontraram igualmenteestamenor variabilidadeno comportamento dos pacientes psicóticos (Bellack \& cols., 1990, Moos, 1968; Trower, 1980). Segundo Trower, este fato poderia ser explicado pela dificuldade que os pacientes possuem de detectar e monitorar os estímulos sociais e mudanças situacionais, assim como os estímulos resultantes dos seus próprios comportamentos, comprometendo sua adaptabilidade e resultando em menor variabilidade comportamental.

Os resultados obtidos na presente pesquisa mostraram que a impressão global de assertividade dos pacientes está relacionadaa componentesverbais enão-verbais específicos do desempenho. Esteconhecimento confirma anecessidade destes pacientes de aprenderem as habilidades sociais básicas requeridas nas interações sociais na comunidade. Um tal conhecimento poderá servir, portanto, para orientar 0 treinamento da assertividade em programas de readaptação psicossocial, visando melhorar o desempenho dos pacientes, demodo a lhes fornecer meios concretos de enfrentamento de situações interpessoais.

Segundo Patterson e colaboradores (2001), o funcionamento social tem sido cada vez mais considerado como um fator central na avaliação da qualidade de vida de pacientespsiquiátricos. Portanto, um melhor funcionamento social dos pacientes pode se refletir em uma melhor reinserção na comunidade e a uma qualidade de vida mais satisfatória.

\section{Referências}

Bandeira, M., Cardoso, C. S., Fernandes, M. L., Resende, R. A. \& Santos, S. C. A. S. (1998). Competência social de psicóticos: Validação social de habilidades específicas. Jornal Brasileiro de Psiquiatria, 47, 217-226.

Bandeira, M. \& Tremblay, L. (1998). Competência social de psicóticos: Um estudo de validação social. Jornal Brasileiro de Psiquiatria, 47, 185192.

Bandeira, M. (1999). Competência social de psicóticos: Parâmetros do treinamento para programas de reabilitação psiquiátrica (E Parte II). Jornal Brasileiro de Psiquiatria, 48, 191-195.

Bandeira, M. (2002). Escala de avaliação de competência social de pacientes psiquiátricos através de desempenho de papéis (EACS). Avaliação Psiológica, 2, 159-171.

Bandeira, M., Machado, E. L. \& Pereira, E. A. (2002). Reinserção social de psicóticos: Componentes verbais e não-verbais do comportamento assertivo, em situações de fazer e receber críticas. Psioologia: Reflexão e Crítica, 15(1), 89-104.

Bellack, A. S. (1983). Recurrent problems in the behavioral assessment of social skill. Behavior Research and Therapy, 21(1), 29-41.

Bellack, A. S., Turner, S. M., Hersen, M. \& Kazdin, A. S. (Orgs.) (1986). An examination of the efficacy of social skills training for chronic schizophrenic patients. Hospital and Community Psychiatry, 35, 10231028.

Bellack, A. S., Morrison, R. L., Mueser, K. T, Wade, J. H. \& Sayer, S. L. (1990). Role play for assessing the social competence of psychiatric patients. Journal of Consulting and Clinical Psychology, 2, 248-255.

Caballo, V. E. (1996). Manual de técnicas de terapia e modificação do comportamento. São Paulo, SP: Santos Livraria.

Cyr, M., Hodgins, S., Gaston, L. E. \& Viens, L. (1990). La vie au sein d'appartements surveillés pour patients psychiattriques chroniques. Revue

Canadienne de Santé Mentale Communautaire, 9, 23-37.

Del Prette, Z. A. P. \& Del Prette, A. (1999). Psicologia das habilidades sociais: Terapia e educação. Petrópolis, RJ: Vozes.

Eisler, R. M., Hersen, M., Miller, P. M. \& Blanchard, E. B. (1975). Situational determinants of assertive behaviors. Journal of Consulting and Clinical Psychology, 43, 330-340.

Farrell, A. D., Rabinowitz, J. A., Wallander, J. L. \& Curran, J. P. (1985). An evaGiation of two formats for the intermediate-level assessment of social skills. Behavioral Assement, 7, 155-171.

Gambrill, E. D. (Org.) (1978). Behavior modification: Handbook of assessment, intervention and evaluation. Washington, D.C.: JosseyBass. 
Hogarty, G. E., Anderson, C. M., Reiss, D. J., Kornblith, S. J., Greenwald, D. P., Ulrich, R. F. \& Carter, M. (1991). Family psychoeducation, social skills training, and maintenance chemotherapy in the aftercare treatment of schizophrenia. Archives of General Psychiatry, 48, 340-347.

Lange, J. L. \& Jakubowski, P. (1976). Responsible assertive behavior. Illinois: Research Press.

Liberman, R. P., Wallace, C. J., Blackwell, C. A., Eckman, T. A., Vaccaro, J. V. \& Kuehnel, T. G. (1993). Innovations in skills training for the seriously mentally ill: The UCLA social and independent living skills modules. Innovations and Research, 2, 43-60.

Merluzzi, T. V. \& Biever, J. (1987). Role-playing procedures for the behaE vioral assessment of social skill: A validity study. Behavioral Assesment, 9, 361-377.

Millbrook, J. M., Farrell, A. D. \& Curran, J. P. (1986). Behavioral components of social skills: A look at subject and confederate behaviors. Behavioral Assessment, 8, 203-220.

Moos, R. H. (1968). Situational analysis of a therapeutic community milieu. Journal of Abnormal Psychology, 73, 49-61.

Mueser, K. T., Bellack, A. S., Douglas, M. S. \& Morrison, R. L (1991). PreEF valence and stability of social skills deficits in schizophrenia. Schizophrenia Research, 5, 167-176.

Mueser, K. T., Bellack, A. S., Randall, L. M \& Wixted, J. T. (1990). Social competence in schizophrenia: Premorbid adjustement, social skill, and domains of functioning. Journal of Psychiatry Research, 24, 51-63.

Mueser, K. T., Wallace, C. J. \& Liberman, R. P. (1995). New developments in social skills training. Behavior Change, 12, 31-40.
Patterson, T. L., Moscona, S., McKibbin, C. L., Davidson, K. \& Jeste, D. V. (2001). Social skills performance assessment among older patients with schizophrenia. Schizophrenia Research, 48, 351-360.

Penn, D. L., Mueser, K. T., Doonan, R. \& Nishith, P. (1995). Relations betE ween social skills and ward behavior in chronic schizophrenia. Schizophrenia Research, 16, 225-232.

Tremblay, L. (1992). Évaluation de la competence sociale de personnes souffrant de troubles mentaux graves: Études de validation sociale. (Relatório n. RS-1725- 089). Montréal, Canada: Conseil Québecois de la Recherche Sociale. (RS-1725-089).

Trower, P. (1980). Situational analysis of the components and processes of behavior of socially skilled and unskilled patients. Journal of Consulting and Clinical Psychology, 48, 327-339.

Wallace, C. J., Liberman, R. P., Mackain, S. J., Blackwell, G. \& Eckman, T. A (1992). Effectiveness and replicability of modules for teaching soci$\mathrm{al}$ and instrumental skills to the severely mentally ill. American Journal of Psychiatry, 149, 654-658.

Zubin, J. \& Spring, B. (1977). Vulnerability: A new view of schizophrenia. Journal of Abnormal Psychology, 86, 103-126.

Sobreasautoras

Marina Bandeira éD outora pela Universitéde Montreal. É Professora Adjunta da Universidade

Federal de São João del Rei.

Esther de Matos Ireno éaluna do Curso deGraduação em Psicologia da UniversidadeFederal de São João del Rei.

Recebido: 22/11/2001

1a Revisão: 29/01/2002

Última Revisão: 04/07/2002

Acite Final: 05/07/2002 